\title{
RESPONSABILIDADE SOCIAL: CONTRA OU A FAVOR?
}

\section{RESPONSABILIDAD SOCIAL: ¿A FAVOR O EN CONTRA?}

\author{
Joana Coeli Ribeiro Garcia - nacoeli@gmail.com \\ Doutora em Ciência da Informação pela Universidade Federal do Rio de \\ Janeiro / Instituto Brasileiro de Informação em Ciência e Tecnologia \\ UFRJ/IBICT. Professora do Departamento de Ciência da Informação e do \\ programa de Pós-graduação em Ciência da Informação (PPGCI) da \\ Universidade Federal da Paraíba (UFPB). \\ Tatiana Falcão de Souza Fernandes -tatianafalc@gmail.com \\ Mestre em Ciência da Informação pelo PPGCI- UFPB. Professora do \\ Departamento de Ciências Contábeis da Universidade Federal do Rio \\ Grande do Norte (UFRN). \\ Jorge Raimundo da Silva - jormundinho@hotmail.com \\ Mestre em Ciência da Informação pelo PPGCI - UFPB Bibliotecário da \\ Universidade Federal de Alagoas (UFAL). \\ Josivan de Oliveira Ferreira - jofer25@hotmail.com \\ Mestre em Ciência da Informação pelo PPGCI- \\ UFPB. Contador.
}

\section{RESUMO}

Introdução: Discute a responsabilidade social (RS) sob a ótica empresarial enfatizando as diferenças que surgem a partir da teoria neoliberal sobre a responsabilidade social empresarial (RSE) e da possibilidade de ações de melhoria da sociedade como um todo. A filantropia é considerada como o início de toda ação de RS.

Objetivo: Compreender os conceitos de responsabilidade social a fim de estabelecer paralelos sobre o que as empresas desenvolvem, ampliando a percepção do que as organizações praticam atualmente.

Metodologia: O artigo é desenvolvido a partir de uma metodologia com abordagem bibliográfica de natureza teórica. 
Joana Coeli Ribeiro Garcia; Tatiana Falcão de Souza Fernandes; Jorge Raimundo da Silva; Josivan de Oliveira Ferreira

Responsabilidade social: contra ou a favor?

Resultados: A partir das diferenças existentes entre filantropia e RS é possível compreender esta última, ultrapassando expectativas econômicas. A ação ética na RS significa que as organizações devem aplicá-la em sua política de gestão e na cultura, incorporando-a às atividades sociais que beneficiam o ser humano.

Conclusão: Numa visão pragmática e realista, conclui-se que a RSE na atuação gerencial das organizações repercute favoravelmente na sociedade, quando desenvolvida de forma contínua e com seu pleno sentido para a sustentabilidade social e ambiental do planeta, além de contribuir para a construção de uma sociedade cidadã por meio da ética e da melhoria das condições de vida de todos.

Palavras-chave: Responsabilidade social empresarial. Ética empresarial. Transformação global. Filantropia.

\section{INTRODUÇÃO}

A sociedade globalizada vive um momento de significativas transformações. Nos últimos trinta anos, a humanidade vê surgir fatos e fenômenos sociais, econômicos, tecnológicos, ambientais e políticos que moldaram este momento especial, em que o conflito e a incerteza são aspectos intangíveis dessa compreensão. Nesse panorama, ressalte-se o pensamento de Santos (2003, p. 19) ao afirmar que "no cenário econômico nacional e internacional, o quadro social atual é preocupante". Isso requer de todos os atores sociais, decisões e condutas que reflitam e intervenham com harmonia entre seus pares nos próximos anos, notadamente para reverter as desigualdades sociais e estabilizar o acesso aos bens essenciais e primordiais, tais como: saúde, educação e emprego.

Nesse horizonte desconhecido, preocupante e desafiador, verifica-se o papel fundamental das instituições, em suas dimensões públicas ou privadas, as quais se compõem essencialmente por indivíduos e por valores, missão, visão, objetivos estratégicos, concepções estruturais e gerenciais.

Torna-se importante, diante das estratégias, seja dos indivíduos e das organizações das quais fazem parte, a adição de reflexão nos processos de tomada de decisão e planejamento estratégico, em que a dimensão econômico-financeira se torna coadjuvante da dimensão social no ambiente competitivo atual. Esta é a defesa de Santos (2003, p. 19) ao observar que "hoje, o lucro como indicativo de empresa de sucesso não é mais uma verdade absoluta, a menos que venha acompanhado do fortalecimento de vínculos comerciais e sociais da empresa". Assim, no âmbito das organizações, não há mais como tratar, a questão social como 
Joana Coeli Ribeiro Garcia; Tatiana Falcão de Souza Fernandes; Jorge Raimundo da Silva; Josivan de Oliveira Ferreira

Responsabilidade social: contra ou a favor?

algo secundário, deixando o poder público como principal, e por vezes único responsável, pois os efeitos da instabilidade são, e serão cada vez mais sentidos por todos.

Mas não apenas pela organização, e sim também por parte dos cidadãos que as compõem, deixando para trás a ideia de que o Estado é o principal ator ou interventor nas questões sociais, cuja origem no modelo keynesiano, volta-se para amenizar e corrigir os efeitos da crise econômica das décadas de 1920 e 1930. Insere-se, pois, no ambiente empresarial, e de forma abrangente nas diversas organizações, uma nova diretriz ética, intrínseca ao negócio. Isto significa dizer que as organizações devem ter responsabilidade social (RS), estritamente ligada à ética cobrada pelos agentes formadores do ambiente competitivo: empresários, gestores, clientes, fornecedores, concorrentes, empregados e sociedade.

A RS configura-se como uma ação que, de alguma forma, contribui direta ou indiretamente para a transformação e melhoria dos diversos segmentos da sociedade, considerando sua atuação positiva ao focalizar questões voltadas à sustentabilidade e à pró-atividade.

Surgida nos Estados Unidos da América, na década de 1960, quando uma empresa resolveu publicar seu balanço anual ou relatório social, causou frisson, originando o que hoje conhecemos como responsabilidade social empresarial (RSE). A iniciativa contábil adotada mundo afora registra manifestações a favor deste comportamento, espalhando-se pela Europa e pelo Brasil. Particularmente na França, Alemanha e Inglaterra, iniciou-se cobrança por maior RS e consolidou-se a necessidade de divulgação dos chamados balanços ou relatórios sociais, configurando-se como uma ação que, de alguma forma, contribui direta ou indiretamente para a transformação da sociedade.

No entanto, é possível encontrar autores cujos argumentos contrariam essas ideias. Para Srour (2000), existem práticas contrárias à RS:

a) Desvio, pelos gestores, da atividade principal da empresa, de geração de lucro e aumento do patrimônio líquido, incorrendo em atitude ilegal;

b) Elevação dos preços dos produtos ou serviços oferecidos como consequência de que as atividades sociais aumentam os custos empresariais;

c) Participação minimizada do governo em ações exclusivamente suas. 
Joana Coeli Ribeiro Garcia; Tatiana Falcão de Souza Fernandes; Jorge Raimundo da Silva; Josivan de Oliveira Ferreira

Responsabilidade social: contra ou a favor?

Como destaca Ashley (2005), os argumentos contra a responsabilidade social das empresas (RSE) têm sido mais fervorosamente articulados por Milton Friedman, embora outros autores, como Neil Chamberlain e Henry Manne, compartilhem de suas ideias. Para eles, a única responsabilidade que a empresa tem é conseguir lucro, otimizar o uso dos recursos organizacionais, e, em consequência, aumentar o retorno do capital dos acionistas. Dessa forma, mantendo o foco nos negócios, ela aumenta sua competitividade e lucratividade.

Para que se possa assumir posição definitiva em relação à $R S$, é necessário conhecer sua essência no contexto contemporâneo; especialmente para que não seja confundida com filantropia que representa atividades esporádicas de caridade, e é como a RS se configura na maioria das organizações. Dessa feita, a RS se constitui objetivo deste ponto de vista, ampliando a percepção do que as organizações praticam e estabelecendo paralelos sobre o que desenvolvem. Metodologicamente, este artigo desenvolve abordagem bibliográfica de natureza teórica para cumprir o objetivo pretendido.

\section{RESPONSABILIDADE SOCIAL}

A política de RSE deve estar integrada em suas diretrizes principais, agregada aos custos operacionais estratégicos e envolvendo todos os colaboradores da organização. Diante dessa diretriz empresarial, a RS, segundo Ashley (2003, p. 56), pode ser definida como:

[...] compromisso que uma organização deve ter com a sociedade, expresso por meio de atos e atitudes que a afetem positivamente, de modo amplo, ou a alguma comunidade, de modo específico, agindo pró-ativamente e coerentemente no que tange a seu papel específico na sociedade e a sua prestação de contas para com ela.

A organização, nesse sentido, assume obrigações de caráter moral, além das estabelecidas em lei, mesmo que não diretamente vinculadas às suas atividades, mas que possam contribuir para o desenvolvimento sustentável dos povos. Numa visão expandida, RS é toda e qualquer ação que possa contribuir para a melhoria da qualidade de vida da sociedade. 
Joana Coeli Ribeiro Garcia; Tatiana Falcão de Souza Fernandes; Jorge Raimundo da Silva; Josivan de Oliveira Ferreira

Responsabilidade social: contra ou a favor?

A contribuição para a construção de um conceito evoluído para a responsabilidade social empresarial nas organizações pode ser observada pelo Banco Mundial, ao estabelecer que:

RSE é o compromisso empresarial de contribuir para o desenvolvimento econômico sustentável, trabalhando em conjunto com os empregados, suas famílias, a comunidade local e a sociedade em geral para melhorar sua qualidade de vida, de maneira que sejam boas tanto para as empresas como para 0 desenvolvimento (BANCO MUNDIAL, 2002 apud KREITLON, 2004, p. 3).

Isto significa que as entidades devem aplicar princípios em suas políticas de gestão, semelhantes a uma cultura que deve ser incorporada às empresas. Além do mais, o discurso de uma preocupação social deve refletir-se em ação, pois não adianta uma empresa pagar mal a seus funcionários, corromper a área de compras de seus clientes, pagar propinas a fiscais do governo e, ao mesmo tempo, desenvolver programas voltados a entidades sociais da comunidade. Essa postura não condiz com uma empresa que quer trilhar um caminho de responsabilidade social.

Outra definição fundamentada pelo Instituto Ethos (2011), o qual menciona RS como:

[...] a forma de gestão que se define pela relação ética e transparente da empresa com todos os públicos com os quais ela se relaciona e pelo estabelecimento de metas empresariais compatíveis com o desenvolvimento sustentável da sociedade, preservando recursos ambientais e culturais para as gerações futuras, respeitando a diversidade e promovendo a redução das desigualdades sociais.

Estas definições remetem às preocupações que afligem a sociedade atual, ou seja, às questões ambientais e de empregabilidade, que se acostam finamente com a capacidade de os indivíduos se manterem ativos e atendidos em suas necessidades básicas. É possível, a partir dessas definições, extraírem-se informações sobre a RSE como algo que vai além de expectativas econômicas e atividades sociais que beneficiam o ser humano. Não se trata de ações paliativas, mas de processos contínuos que tenham reflexos futuros e alinhados com a visão estratégica da organização que, de acordo com Ashley (2003), é um conceito em 
Joana Coeli Ribeiro Garcia; Tatiana Falcão de Souza Fernandes; Jorge Raimundo da Silva; Josivan de Oliveira Ferreira

Responsabilidade social: contra ou a favor?

construção. Assim encontram-se empresas praticando tanto a filantropia quanto a RS.

[...] ainda é possível no Brasil, encontrar empresas praticando o assistencialismo, enquanto outras desenvolvem por meio de parcerias a responsabilidade social corporativa no contexto de ideias ampliadas, envolvendo tanto empresas privadas como públicas e da sociedade civil, de qualquer natureza, seus empregados, seus stakeholders e a sociedade como um todo. Muitas vezes atendendo ao constante nas políticas públicas (GARCIA, 2011, p. 28).

Para a prática da responsabilidade social corporativa (RSC), é necessário atender a 4 importantes características, entre elas:

a) Caráter Plural, no sentido de que seu compromisso de prestar contas deixa de ser apenas para com os sócios da organização, a partir do momento em que as atividades desenvolvidas por elas passam as fronteiras da instituição. Assim, "O mercado deve agora prestar contas aos funcionários, à mídia, ao governo, ao setor não governamental e ambiental e, por fim, às comunidades com que opera." (RESPONSABILIDADE..., 2011).

O caráter plural reflete-se no compromisso de prestação de contas das ações desenvolvidas pela empresa a todas as partes envolvidas no ambiente interno e externo à organização, ou seja, além dos sócios, as informações satisfazem aos funcionários, à mídia, ao governo, às organizações não governamentais e às comunidades circunvizinhas da organização. É importante salientar que o acesso à informação proporciona maior conscientização das pessoas em relação aos fatores de influência no desenvolvimento de produtos e serviços, afetando a sociedade de maneira geral.

b) Caráter Distributivo tem em vista que a RS perpassa "[...] toda a cadeia produtiva, não somente o produto final deve ser avaliado por fatores ambientais ou sociais, mas o conceito é de interesse comum." (RESPONSABILIDADE..., 2011).

Percebe-se que o caráter distributivo reflete-se em todo o processo de produção, não se resumindo apenas ao produto final, mas também aos efeitos gerados ao meio ambiente, ao cliente, ao concorrente e a toda sociedade de maneira que a partir da RSE, o setor de produção deve ser informado de todos os efeitos provocados.

c) Caráter Sustentável, pois a "responsabilidade social anda de mãos dadas com o conceito de desenvolvimento sustentável." (RESPONSABILIDADE..., 2011). 
Joana Coeli Ribeiro Garcia; Tatiana Falcão de Souza Fernandes; Jorge Raimundo da Silva; Josivan de Oliveira Ferreira

Responsabilidade social: contra ou a favor?

Nota-se, nos dias atuais, que o caráter sustentável reflete a responsabilidade de produzir para atender às necessidades da sociedade sem trazer consequências danosas aos recursos que serão utilizados pelas gerações futuras.

d) Caráter Transparente visa que "A globalização traz consigo demandas por transparência." (RESPONSABILIDADE..., 2011). Atitudes e ações que possam ser acompanhadas por todos os membros da sociedade.

Esta característica da RSE reflete, em certa medida, o que ocorre nos últimos 10 anos, proporcionado pela internacionalização dos mercados, a qual provocou mudanças significativas na maneira de agir diante dos concorrentes, clientes, fornecedores e, em última instância, da sociedade. A RSE passou a ser um requisito indispensável para as organizações que deixaram de ter uma visão restrita para uma nova perspectiva de atuação no mercado e a transparência de suas ações refletidas nos relatórios anuais para que a organização possa ser avaliada em todas as suas modalidades.

Figura 1 - Características da Responsabilidade Social Corporativa

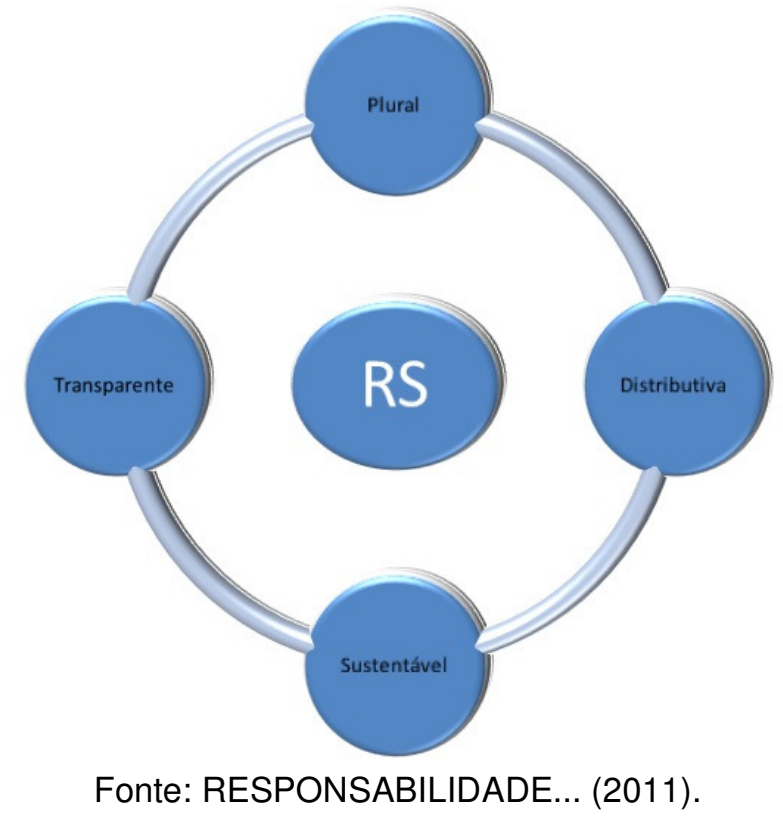

\section{FILANTROPIA}

Reforçamos que a filantropia é a ação que inicia a RS. Friedman (1984) critica como a RSE é praticada atualmente na sociedade ao destacar que a única responsabilidade que a empresa tem é a de conseguir lucro; no entanto, agindo assim a empresa obtém divulgação positiva por meio do marketing e, 
Joana Coeli Ribeiro Garcia; Tatiana Falcão de Souza Fernandes; Jorge Raimundo da Silva; Josivan de Oliveira Ferreira

Responsabilidade social: contra ou a favor?

consequentemente, aumenta o retorno do capital para os acionistas. Embora não seja uma forma ética de atender às necessidades da sociedade, não se pode negar que ela faz algo positivo. Por outro lado, ainda é o autor quem explicita que ao cumprir aquilo para o qual foi criada, a empresa torna-se responsável:

[...] ao gerar novos empregos, pagar salários justos e melhorar as condições de trabalho, além de contribuir para o bem-estar público ao pagar seus impostos. A empresa que desvia recursos para ações sociais pode estar prejudicando sua competitividade [...] deve manter o foco nos negócios (FRIEDMAN, 1984, p. 320).

Com esse entendimento, Canto-Sperber (2007, p. 235) esclarece que as empresas podem beneficiar "[...] o mundo exterior à empresa, ao mesmo tempo em que favorece a reputação ou a imagem da própria empresa."

É provável que a partir desse pensamento haja alinhamento do conceito com o de RS, uma vez que parte dos administradores e dirigentes de grandes corporações se mantém reticentes em incorporar ao planejamento estratégico objetivos de desenvolvimento social alinhado com os financeiros, ou seja, para muitos fazer filantropia e caridade é praticar a RS. Eles se apoiam no pensamento tecnicista do modelo neoliberal, vigente, notadamente, nas décadas de 1980 e 1990, cuja principal referência se deu no pensamento de Freeman (1984), citado por Kreitlon (2004), que defendia a ideia de responsabilidade das empresas desenvolvida para atender aos interesses dos acionistas, substituindo a ótica de que o gestor não tinha responsabilidade com os stakeholders, a qual envolve as "[...] três correntes teóricas dedicadas ao estudo das relações entre ética, empresas $e$ sociedade." (KREITLON, 2004, p. 6).

Garcia (2011, p. 27), por sua vez, salienta que no campo da iniciativa privada, a responsabilidade social foi concebida como uma atividade neoliberal uma vez que tais ações eram executadas com o intuito de obter lucros. Eram feitas doações às "[...] instituições necessitadas, recebendo delas um documento para, quando do acerto de contas com o Imposto de Renda, abater o valor em sua declaração anual [...]". Isto se caracteriza como uma pseudorresponsabilidade social, ou seja, uma filantropia travestida de RS, pois estas ações não passam de um jogo de marketing com o intuito de proporcionar destaque à Instituição que promove tais ações.

De acordo com Santos (2003, p. 20), "O que não é responsabilidade social: ações esporádicas, doações e outros gestos de caridade não vinculados à estratégia 
Joana Coeli Ribeiro Garcia; Tatiana Falcão de Souza Fernandes; Jorge Raimundo da Silva; Josivan de Oliveira Ferreira

Responsabilidade social: contra ou a favor?

empresarial." Nesse caso, as entidades que acreditam ser socialmente responsáveis, na verdade, estão fazendo paternalismo, seja por iniciativa pessoal, por sua corporação ou por seus dirigentes.

Ainda é Garcia (2011, p. 28) que, ao estudar RS em instituições de ensino superior na cidade de João Pessoa, afirma que "[...] a responsabilidade social se constituía e ainda se constitui em atividades isoladas de filantropia, paternalismo ou mero assistencialismo." Destacamos que por trás da filantropia existem diversos interesses dentre os quais, a obtenção de lucros. Em uma só palavra, à filantropia não interessa tão somente o bem-estar social, sendo esta considerada como a primeira atividade relacionada à $\mathrm{RS}$.

Por outro lado, entendem-se como benéficas as ações que algumas instituições praticam, pois de alguma forma estas iniciativas amenizam os problemas sociais, mesmo que não venham a resolvê-los, uma vez que esta não é missão de tais instituições. Este pensamento encontra apoio no utilitarismo: filosofia defendida por Stuart Mill e Jeremy Bentham, a qual parte do pressuposto de que a atividade humana deve objetivar a felicidade e o bem-estar dos indivíduos em que cada ação é considerada boa do ponto de vista moral quando ela contribui para o bem-estar coletivo.

Rachels (2004, p. 151) alerta que:

O utilitarismo clássico, a teoria de Bentham e Mill, pode ser resumido em três proposições: primeiro, deve-se julgar que as ações são moralmente certas ou erradas somente em função das suas consequências. Nada mais importa. Segundo, ao avaliar as consequências, a única coisa que interessa é a quantidade de felicidade ou infelicidade criada. Tudo o mais é irrelevante. Terceiro, a felicidade de cada pessoa conta da mesma maneira.

Diante do contexto, faz-se necessário evidenciar as diferenças entre filantropia e responsabilidade social. Melo Neto e Froes (2001) destacaram as diferenças relevantes em relação aos dois conceitos aqui expostos. 
Joana Coeli Ribeiro Garcia; Tatiana Falcão de Souza Fernandes; Jorge Raimundo da Silva; Josivan de Oliveira Ferreira

Responsabilidade social: contra ou a favor?

Quadro 1 - Diferenças entre Filantropia e Responsabilidade Social

\begin{tabular}{|l|l|}
\hline \multicolumn{1}{|c|}{ Filantropia } & \multicolumn{1}{c|}{ Responsabilidade Social } \\
\hline Ação individual e coletiva & Ação coletiva \\
\hline Fomento da caridade & Fomento da cidadania \\
\hline Base assistencialista & Base estratégica \\
\hline Restrita a empresários abnegados & Extensiva a todos \\
\hline Prescinde de gerenciamento & Demanda gerenciamento \\
\hline Decisão individual & Decisão consensual \\
\hline
\end{tabular}

Fonte: Melo Neto e Froes, 2001

É possível, a partir dessas diferenças, extrair informações sobre a RSE como algo que vai além de expectativas econômicas e atividades sociais que beneficiam o ser humano. A questão ética entra em ação e significa que as entidades devem aplicar princípios em sua política de gestão, semelhante a uma cultura que deve ser incorporada ao pensamento da empresa.

\section{A QUESTÃO ÉTICA E A RESPONSABILIDADE SOCIAL}

A ética, de forma geral, se confunde e se relaciona com o conceito de moral. Segundo Gomes (2011), moral é entendida como "[...] regras de conduta que organizam as relações interpessoais forçadas pelo hábito e que ordenam nossos comportamentos." Portanto, a moral atua como um agente regulador dos valores e comportamentos que, em determinada sociedade e em dada época, são considerados legítimos pelos indivíduos, como uma religião.

Nesse sentido, a moral empresarial / corporativa pode ser definida como:

[...] conjunto daqueles valores e normas que, dentro de uma determinada empresa, são reconhecidos como vinculantes. A ética empresarial reflete sobre as normas $e$ valores efetivamente dominantes em uma empresa, interroga-se pelos fatores qualitativos que fazem com que determinado agir seja um agir bom (LEISINGER; SCHIMITT, 2001, p. 22).

Para Veloso (2006, p. 7), a RSC define o novo ethos, tornando obrigação para as organizações a prática pautada numa conduta ética ao mesmo tempo em que seguem os valores morais, provocando a criação de diretrizes nas organizações, ou 
Joana Coeli Ribeiro Garcia; Tatiana Falcão de Souza Fernandes; Jorge Raimundo da Silva; Josivan de Oliveira Ferreira

Responsabilidade social: contra ou a favor?

seja, "preocupação com atitudes éticas e moralmente corretas que afetam todos os públicos / stakeholders envolvidos." Esta deve ser uma das preocupações das organizações que buscam uma conduta diferenciada do ponto de vista ético e moral, refletindo assim um resultado que busca atender a todas as partes interessadas, o que reflete certa dependência em suas ações. Assim, as atitudes éticas e moralmente corretas podem promover mudanças de comportamentos e de valores nas instituições.

O reconhecimento e a valorização da importância na contribuição ao meio ambiente é condição indispensável a toda empresa, tendo em vista que ela está inserida na sociedade. Veloso $(2006$, p. 7$)$ afirma que o "respeito ao meio ambiente e contribuição para sua sustentabilidade em todo o mundo" devem fazer parte da missão de uma organização, enquanto instituição séria e comprometida com a sustentabilidade ambiental. Dessa forma, as ações relacionadas ao meio ambiente refletem o conceito de desenvolvimento sustentável, que busca a utilização dos recursos ambientais de modo responsável para atender às necessidades das gerações futuras. Ainda acrescenta a autora que o envolvimento nas comunidades poderá proporcionar "[...] desenvolvimento econômico e humano dos indivíduos ou até atuando diretamente na área social, em parceria com governos ou isoladamente." (VELOSO, 2006, p. 7). Características essas que diferenciam as organizações éticas responsáveis das demais.

Nos dias atuais, com o imperativo provocado pela globalização causadora de grandes transformações socioeconômicas, a ética, através da RS, influencia os rumos da economia global, considerando que a corrida por lucros obedece às leis $\mathrm{e}$ segue comportamentos voltados à comunidade na qual está inserida. Nesse cenário, a forma como os produtos são apresentados tende a sofrer mudanças, pois a própria dinâmica do mercado impõe às empresas um comportamento diferenciado. Ou seja, é de fato a sociedade que dita os padrões éticos e morais a serem seguidos pelas grandes e pequenas empresas.

Dito de outra forma, o efeito que a globalização exerce nas empresas pode ser entendido como uma resposta às exigências que o mercado local faz devido ao acesso às tecnologias de informação, que possibilitaram maior dinamicidade no tocante às trocas de informações. Assim, há obtenção de mais informações acerca de variados temas. 
Joana Coeli Ribeiro Garcia; Tatiana Falcão de Souza Fernandes; Jorge Raimundo da Silva; Josivan de Oliveira Ferreira

Responsabilidade social: contra ou a favor?

Com base em Garcia (2011), adiantamos que de forma geral quando uma indústria lança no mercado um produto, ela procura fazê-lo seguindo as recomendações das agências de proteção ambiental ou de proteção aos animais, de modo que não agrida a natureza, agregando valor ao seu produto. Tais atitudes evidenciam a preocupação com o bem-estar do homem, com progresso econômico da comunidade na qual a corporação está inserida e com a consciência ambiental. Aqui cabe destacar o conceito ampliado de RS trabalhado por Garcia (2011, p. 33), que engloba "[...] a gestão ambiental e gestão de fornecedores, com a finalidade de criar a sustentabilidade ambiental, econômica e social promovida pelos impactos sociais da organização."

É essa consciência de pertencimento à sociedade que irá definir ações sociais e práticas que a organização desempenhará num contexto amplo. Veloso (2006, p. 8) acrescenta que "[...] toda sociedade funciona de acordo com princípios, valores e tradições culturais específicos, que determinam os pensamentos e comportamento dos indivíduos." Concluindo que: "Não há indivíduos, empresas ou países sem cultura." Nesse sentido, a responsabilidade social contribui para a criação de vínculos sólidos com clientes e fornecedores e, sobretudo, com a sociedade na qual a empresa se insere.

Nessa perspectiva, torna-se necessário conhecer e praticar a responsabilidade social no contexto contemporâneo. É nesse cenário que a RS se apresenta no início do século XXI. Assim, não se concebe que uma empresa, que tenha pretensões num mercado cada vez mais competitivo, fuja dessas responsabilidades que são legais e moralmente corretas. A RS deve fazer parte das prioridades e competências das instituições que, de uma forma ou de outra, estão a serviço da sociedade.

\section{CONSIDERAÇÕES FINAIS}

A partir da compreensão dos conceitos de RS e filantropia, observamos que uma empresa, por mais que ofereça para os seus consumidores e parceiros produtos e processos eficientes, se não tiver a visão clara e a gestão eficaz sobre suas responsabilidades para com os fatores éticos de atuação social em seu ambiente competitivo, poderá comprometer seus objetivos. 
Joana Coeli Ribeiro Garcia; Tatiana Falcão de Souza Fernandes; Jorge Raimundo da Silva; Josivan de Oliveira Ferreira

Responsabilidade social: contra ou a favor?

Assim, é missão da empresa adotar um modelo de gestão, tendo como alicerces a ética corporativa e o desenvolvimento sustentável fundamentados nas 4 características necessárias à implementação da RSE já destacadas, a saber: Caráter Plural, Distributivo, Sustentável e o Caráter Transparente, de modo que contribua para a preservação do meio ambiente, melhor distribuição de renda, aumento do desenvolvimento, repercutindo numa melhor qualidade de vida, satisfação e motivação dos empregados. Consequentemente, estas ações poderão trazer para a organização aspectos como maior facilidade de acesso ao capital dos investidores, fortalecimento da marca, aumento das vendas e facilidade na decisão das metas, já que elas condizem com normas e políticas vigentes no governo e na sociedade.

Entendemos que esse fenômeno se amplia com a globalização da economia, uma vez que a mesma provoca mudanças de comportamentos ao permitir que as diversas culturas se aproximem cada vez mais, forçando as organizações a respeitarem e se adaptarem às diferenças culturais, tornando-se socialmente responsáveis com relação ao contexto sociocultural e sobrepondo-se ao dever do Estado.

Daí, pode também surgir uma nova consciência das famílias perante os produtos e serviços que estão dispostos a consumir, que levam em consideração outros fatores intangíveis, não somente relacionados à qualidade tecnológica ou ao preço, mas referentes a critérios culturais, valores éticos e preocupação com o futuro sustentável, ou seja, qualidade de vida almejada pelas famílias.

A discussão acerca da temática apresentada neste texto se faz necessária para ampliar a percepção do que as organizações praticam atualmente. Numa visão pragmática e realista sobre a temática das visões aplicadas no mundo dos negócios, entendemos que a responsabilidade social, no âmbito da atuação gerencial nas organizações, repercute favoravelmente na sociedade, desde que a sua aplicação seja desenvolvida de forma contínua e de acordo com o seu pleno sentido, ou seja, de forma distinta da prática filantrópica.

Ao assumir essa postura, as organizações poderão contribuir para construção de uma sociedade melhor, mais justa, mais solidária, com menos corrupção e por meio da ética e do desenvolvimento ambiental para a sustentabilidade do planeta. Conclui-se que a RSE, na atuação gerencial das organizações e com foco dirigido para a sustentabilidade social e ambiental do planeta, contribui para a construção de 
Joana Coeli Ribeiro Garcia; Tatiana Falcão de Souza Fernandes; Jorge Raimundo da Silva; Josivan de Oliveira Ferreira

Responsabilidade social: contra ou a favor?

uma sociedade cidadã por meio da ética e da melhoria das condições de vida para todos.

\section{REFERÊNCIAS}

ASHLEY, Patrícia Almeida. Responsabilidade social nos negócios. São Paulo: Saraiva, 2003.

. (Coord.). Ética e responsabilidade social nos negócios. São Paulo: Saraiva, 2005.

CANTO-SPERBER, Monique. Dicionário de ética e filosofia moral. São Leopoldo: Unisinos, 2007.

FRIEDMAN, Milton. Capitalismo e liberdade. São Paulo: Abril Cultural, 1984.

GARCIA, Joana Coeli Ribeiro. Responsabilidade social universitária e a população negra. In: AQUINO, Mirian de Albuquerque; GARCIA, Joana Coeli Ribeiro (Org.) Responsabilidade ético-social das universidades públicas e educação da população negra. João Pessoa: Editora Universitária UFPB, 2011. v. 1, p. 23-41.

GOMES, Renato. Moral e ética são a mesma coisa? Disponível em: <http://artigos.netsaber.com.br/resumo_artigo_17930/artigo_sobre_moral_e_etica_s ao_a_mesma_coisa>. Acesso em: 29 out. 2011.

INSTITUTO ETHOS. O que é responsabilidade social empresarial. 2011. Disponível em:

<http://www1.ethos.org.br/EthosWeb/pt/29/o_que_e_rse/o_que_e_rse.aspx>. Acesso em: 25 out 2011.

KREITLON, Maria Priscilla. A ética nas relações entre empresas e sociedade: fundamentos teóricos da responsabilidade social empresarial. In: ENCONTRO DA ASSOCIAÇÃO NACIONAL DE PÓS-GRADUAÇÃO E PESQUISA EM ADMINISTRAÇÃO - EnANPAD, 28., 2004, Curitiba. Anais... Curitiba: ANPAD, 2004. p.1-15.

LEISINGER, Klaus Michael; SCHIMITT, Karin. Ética empresarial: responsabilidade global e gerenciamento moderno. Petrópolis: Vozes, 2001.

MELO NETO, Francisco Paulo de; FROES, César. Gestão da responsabilidade social: o caso brasileiro. Rio de Janeiro: Qualitymark, 2001.

RACHELS, James. Elementos de filosofia moral. Lisboa: Gradiva, 2004.

RESPONSABILIDADE social? 2011. Disponível em:

$<$ http://www.responsabilidadesocial.com/institucional/institucional_view.php?id=1>. Acesso em: 20 out. 2011. 
Joana Coeli Ribeiro Garcia; Tatiana Falcão de Souza Fernandes; Jorge Raimundo da Silva; Josivan de Oliveira Ferreira

Responsabilidade social: contra ou a favor?

SANTOS, Elenice C. Roginski M. Responsabilidade social ou filantropia? Sanare:

Revista Técnica da Sanepar, Curitiba, v. 20, n. 20, p. 18-27, jul./dez. 2003.

SROUR, Robert Henry. Ética empresarial. Rio de Janeiro: Campus, 2000.

VELOSO, L. H. M. Ética, valores e cultura: especificidades do conceito de responsabilidade social corporativa. In: ASHLEY, P. A. (Coord.). Ética e responsabilidade social nos negócios. 2.ed. São Paulo: Saraiva, 2006.

Title

Social responsibility: for or against?

\section{Abstract}

Introduction: It discusses the social responsibility (SR) under the business perspective emphasizing the differences that arise from the neoliberal theory on corporate social responsibility (CSR) and the possibility of improvement actions of society as a whole. Philanthropy is regarded as the beginning of all SR action.

Objective: To understand the concepts of social responsibility in order to establish parallel on what companies develop, increasing the perception of what the organizations currently practice.

Methodology: The article is developed from a methodology with bibliographic approach of theoretical nature.

Results: From the differences between philanthropy and RS is possible to understand this as overcoming economic expectations. The ethical action in the RS means that organizations must apply it in their policy management and culture, incorporating the social activities that benefit humans.

Conclusion: In a pragmatic and realistic view, it is concluded that CSR in management practice of organizations reflects positively in society, when it is developed continuously and with its full sense for the planet's social and environmental sustainability, besides contributing to building a citizen society through ethics and the improvement of living conditions for all.

Keywords: Corporate social responsibility. Corporate ethics. Global transformation. Philanthropy.

\section{Título}

Responsabilidad social: ¿a favor o en contra?

\section{Resumen}


Joana Coeli Ribeiro Garcia; Tatiana Falcão de Souza Fernandes; Jorge Raimundo da Silva; Josivan de Oliveira Ferreira

Responsabilidade social: contra ou a favor?

Introducción: habla sobre la responsabilidad social (RS), bajo la perspectiva de negocios haciendo hincapié en las diferencias que surgen de la teoría neoliberal de la responsabilidad social corporativa (RSC) y la posibilidad de acciones de mejora de la sociedad en su conjunto. La filantropía es considerado como el principio de toda acción RS.

Objetivo: Comprender los conceptos de responsabilidad social para establecer paralelos en lo que desarrollan las empresas, el aumento de la percepción de las organizaciones en la actualidad la práctica.

Metodología: El artículo se desarrolla a partir de un enfoque bibliográfico metodología de carácter teórico.

Resultados: De las diferencias entre la filantropía y la RS es posible entender esto como la superación de las expectativas económicas. La acción ética en la RS significa que las organizaciones deben aplicar en su política de gestión y en la cultura. Esto para que la incorporación en las actividades sociales beneficien a los seres humanos.

Conclusión: En una visión pragmática y realista, se concluye que la RSE en la gestión de actividades de las organizaciones refleja positivamente en la sociedad, cuando se desarrollan de forma continua y con su pleno significado a la sostenibilidad social y ambiental del planeta, y contribuir a la construcción una sociedad ciudadana a través de las condiciones de vida éticos y mejorando para todos.

Palabras clave: Responsabilidad social empresarial. Ética en los negócios. Transformación global. Filantropía.

Recebido em: 18.05.2012

Aceito em: 28.03.2015 